\title{
$\mathrm{PH} 100_{\text {debate }}$
}

a debate Repositorios y redes sociales académicas para la transferencia del conocimiento abierto

| coordina Remedios Melero Melero

\section{Archivo y difusión de contenidos 3D de elementos patrimoniales en repositorios institucionales y plataformas comerciales}

\author{
Álvaro Rodríguez Miranda, Jaione Korro Bañuelos, José M. Valle Melón | Laboratorio de Documentación Geométrica del \\ Patrimonio, Universidad del País Vasco/Euskal Herriko Unibertsitatea
}

URL de la contribución <www.iaph.es/revistaph/index.php/revistaph/article/view/4641>

Los modelos tridimensionales tienen una gran importancia a la hora de representar y difundir diferentes tipos de elementos patrimoniales, desde piezas de museos, yacimientos arqueológicos, edificios (tanto en su estado actual como mostrando recreaciones de cómo pudieron haber sido en el pasado), etc. Por este motivo, son cada vez más habituales en los conjuntos de información que pueden generarse en los diferentes trabajos e investigaciones. Sin embargo los repositorios institucionales no disponen de las herramientas apropiadas para dar visibilidad a este tipo de datos (más allá de su almacenamiento y descarga como cualquier otro tipo de fichero) y esto ha dado pie a que plataformas comerciales, con el caso paradigmático de SketchFab ${ }^{\circledR}$, hayan tomado ventaja y, actualmente, sean las referencias principales para el público interesado en este tipo de contenidos.

En estas líneas se ofrecen algunas pinceladas sobre el recorrido de los contenidos 3D en los repositorios institucionales, para lo cual se hará referencia a diferentes documentos de trabajo de Europeana. Este repaso nos permitirá establecer cuál es la situación actual y vislumbrar propuestas de actuación que permitan compaginar las facilidades y espectacularidad que ofrecen las herramientas comerciales con la preservación y soporte riguroso de los repositorios.

Desde sus inicios los repositorios se han centrado en documentos textuales (principalmente, soportados por ficheros PDF), imágenes (de las cuales también hay diversos formatos muy extendidos y con buenas características para su difusión y preservación) y, en menor medida, audio y vídeo. Recientemente, se ha comenzado a prestar cada vez más atención a los contenidos $3 D$, pero no es un tema sencillo, entre otros motivos por- que no existe una adecuada normalización de los posibles formatos, ni visores web que permitan acceder a estos contenidos de manera ágil para usuarios no especializados; además, los tamaños de los ficheros suelen ser muy grandes lo que ralentiza las descargas y utilización. A finales de 2015, el propio marco de publicación de Europeana (EUROPEANA, 2015) indicaba que aún no se contaba con suficiente experiencia para dar recomendaciones, a pesar de que ya existía la opción de identificar los recursos como 3D, de hecho, la última versión de la guía de publicación (v. 1.8 de julio 2019) todavía no ofrece información a este respecto (EUROPEANA, 2019). Con el fin de paliar esta situación, durante el año 2019, se puso en funcionamiento un grupo de trabajo específico cuyas conclusiones se han publicado recientemente (FERNIE, 2020).

Por mencionar algunos de los datos del informe del grupo de trabajo, se podría indicar que en la revisión de algo más de 8.200 contenidos catalogados como 3D en Europeana se encontró bastante confusión en lo referente a qué se debe catalogar como 3D y una gran disparidad de formatos. Además, se da la circunstancia de que la mayoría de los recursos utilizaban PDF-3D como formato de los ficheros, el cual es un formato que ha dejado de ser soportado por su creador Adobe ${ }^{\circledR}$. Finalmente, el informe del grupo de trabajo realiza algunas recomendaciones como que los contenidos se identifiquen correctamente como 3D, que exista una previsualización en forma de imagen 2D (a la espera de que exista disponibilidad de visores 3D que puedan emplearse directamente dentro de Europeana), que los metadatos sean acordes a los estándares utilizados en Europeana, la utilización de formatos ampliamente aceptados por la industria (aunque la lista de posibilidades es aún amplia) y un sis- 


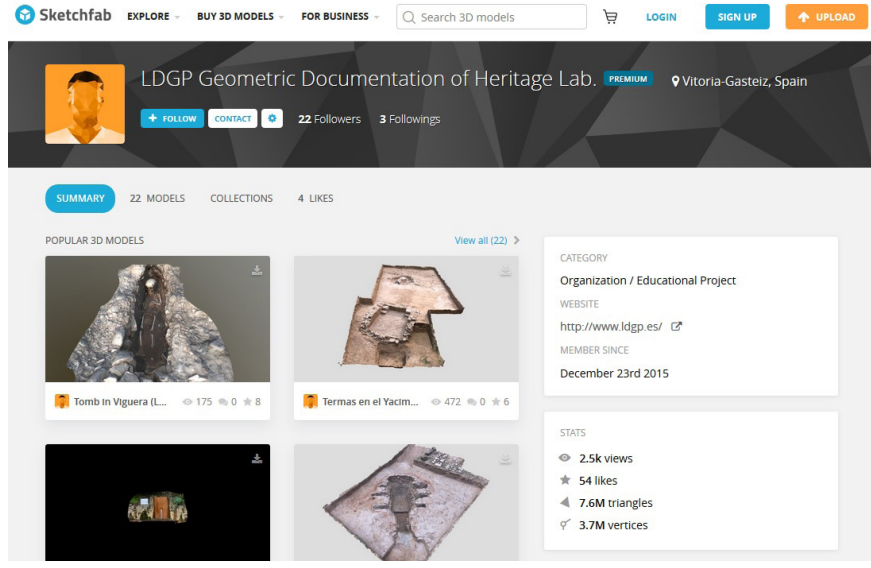

Vista de la cuenta del Laboratorio de Documentación Geométrica del Patrimonio (UPV/EHU) en SketchFab®

tema de licencias acordes con la reutilización que se espere de los productos.

De forma paralela, durante estos últimos años se han ido desarrollando plataformas comerciales para la difusión de contenidos 3D en la que los usuarios pueden abrir sus propias cuentas, subir modelos de manera muy sencilla sin prácticamente tener que preocuparse por el formato de entrada, visualizarlos de manera interactiva online, hacer el seguimiento de otros usuarios, descargar información, analizar el número de visitas, realizar compras y ventas, etc. Básicamente se trata de una versión adaptada al mundo 3D de lo que representa una red social con una tienda virtual. Además, es posible insertar los modelos 3D alojados y mostrarlos en páginas web y otras redes sociales o profesionales, como Facebook, Twitter, Google+, Pinterest, LinkedIn, etc., configurando opciones como el tamaño de la ventana, forma de visualización, anotaciones, etc.

La popularidad de estos sitios, entre los que cabe destacar el mencionado SketchFab®, es enorme entre los usuarios (en febrero de 2020 el blog de la compañía indicaba que el número de miembros superaba los 3 millones, con más de 300.000 modelos descargables de forma libre de entre los varios millones almacenados por los usuarios para su uso personal o comercial) e incluso son numerosas las instituciones culturales, más de 200, las que se han animado a distribuir sus contenidos a través de estas plataformas. A modo de ejemplo se pueden citar, en el ámbito internacional, The British Museum (270 modelos) o The Smithsonian Institution (64 modelos) y, en el ámbito nacional, el Museo Arqueológico Nacional (30 modelos), Museu d'Arqueologia de Catalunya (107 modelos), la Real Academia de Bellas Artes de San Fernando (94 modelos) o el Museo de los Bañales (51 modelos).

Asimismo, Sketchfab® es la plataforma de difusión de interesantes proyectos relativos a la difusión de modelos 3D de elementos culturales (algunos ya destruidos) situados en zonas de conflicto bélico o que han sufrido desastres naturales. Por otro lado, es muy activa en la investigación de aplicaciones de realidad aumentada, anotación de contenidos, técnicas de animación y visualización, etc.

No obstante el debate sigue siendo el mismo que con otras iniciativas comerciales, es decir, hasta qué punto una institución cultural y/o científica debe basar sus políticas de difusión y preservación en una herramienta de estas características; evidentemente, sin tener que renunciar a los beneficios que su uso reporta a la organización. A este respecto, un modo de actuación que se

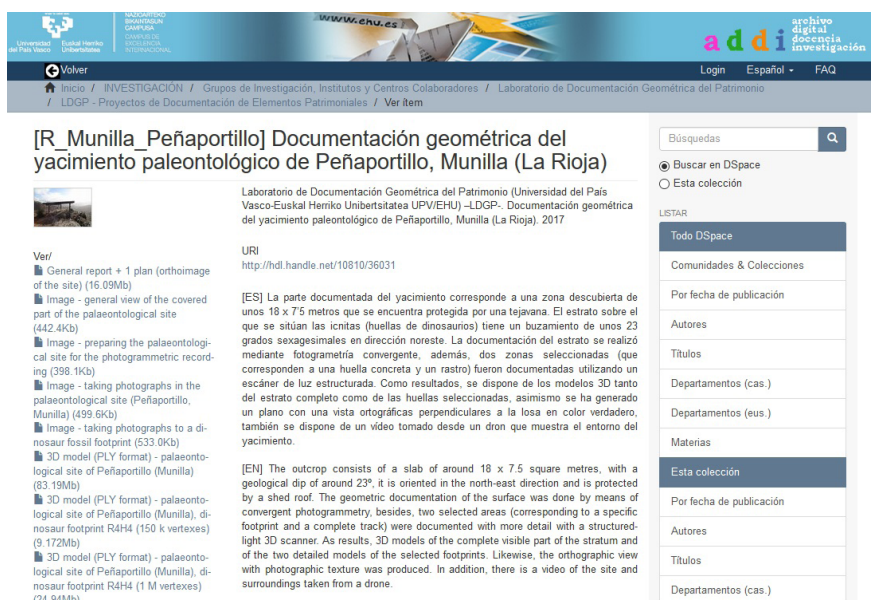

Vista de un registro de un proyecto desarrollado por Laboratorio en el repositorio institucional de la Universidad del País Vasco (ADDI) 
a debate Repositorios y redes sociales académicas para la transferencia del conocimiento abierto

| coordina Remedios Melero Melero

está proponiendo por diversas fuentes consiste en utilizar la herramienta comercial a modo de escaparate para la difusión de los datos, donde se disponga de versiones reducidas que permitan enlazar con los recursos almacenados en los repositorios para aquellos usuarios que deseen acceder a la información detallada. De esta manera estaríamos empleando la "red social" a modo de buscador y visualizador, complementando así las posibilidades de localización y acceso a la información de referencia, la cual estaría disponible de forma abierta y a máxima resolución en el repositorio, junto al resto de la información de contexto, que soporta un modelo tridimensional científico.

A modo de ejemplo, las imágenes que acompañan este texto muestran la cuenta en SketchFab ${ }^{\circledR}$ de nuestro laboratorio y un registro con contenidos 3D almacenados en el repositorio institucional. La primera proporciona un acceso interactivo a los modelos y es utilizada, principalmente, con fines docentes y de difusión ágil e inmediata. Por otro lado, los modelos almacenados en el repositorio tienen que ser descargados por los usuarios para utilizarlos en sus propios equipos, en contrapartida, el registro se presenta abundantemente documentado (está disponible la memoria completa de actuación, planos, fotografías de documentación y un rico conjunto de metadatos descriptivos), su permanencia a lo largo del tiempo está asegurada y se encuentra accesible dentro de las redes de ciencia abierta.

\section{BIBLIOGRAFÍA}

- EUROPEANA (2015) The more you give the more you getEuropeana Publishing Framework (versión española) <http:// hdl.handle.net/10421/8991> [Consulta: 16/04/2020]

- EUROPEANA (2019) Europeana Publishing Guide v. 1.8. A guide to the metadata and content requirements for data partners publishing material in Europeana Collections <https:// pro.europeana.eu/files/Europeana Professional/Publications/ Europeana\%20Publishing\%20Guide\%20v1.8.pdf> [Consulta: 16/04/2020]

- FERNIE, K. (2020) 3D content in Europeana task force. Version $1.0<$ https://pro.europeana.eu/files/Europeana_Profe
ssional/Europeana Network/Europeana Network Task For

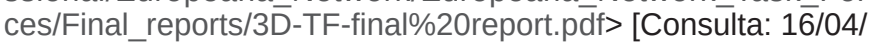
2020] 